\title{
Creep of geopolymeric concrete obtained from mining tailings
}

\author{
F.A. Huamán-Mamani ${ }^{1}$, J.F. Gamarra-Delgado ${ }^{1}$, J.J. Paredes-Paz ${ }^{1}$, V.C. Bringas-Rodríguez ${ }^{1}$, \\ D.L. Mayta-Ponce ${ }^{1}$ and G.P. Rodríguez-Guillén ${ }^{1}$ \\ ${ }^{1}$ Grupo de Investigación en Ciencia y Tecnología de Materiales, Departamento de Ciencias Naturales, Universidad \\ Católica San Pablo, Arequipa, Perú \\ Urb. Campiña Paisajista, Quinta Vivanco s/n, Arequipa 04001, Perú \\ fhuaman@ucsp.edu.pe; frank.gamarra23@gmail.com; janice.paredes@ucsp.edu.pe; veronicawnh@gmail.com; \\ dlmayta@ucsp.edu.pe; gprodriguez@ucsp.edu.pe
}

\begin{abstract}
Geopolymeric materials have recently been considered a revolutionary class of materials, due to the diversity of applications where they can be used, this derived from their good mechanical resistance, thermochemical stability and good fire resistance. From 1970 to the present, a notable increase has been observed in the number of scientific publications dealing with the synthesis and applications of geopolymeric materials with industrial application. Several publications have reported geopolymers as alternative materials to Portland cement, which will allow having a green construction industry in the coming years. The elaboration of geopolymeric materials is relatively simple, beginning with the identification of a source rich in amorphous aluminosilicates and a hardening compound (mainly alkaline in nature) which are properly mixed until a homogeneous and workable paste is obtained, then can harden at room temperature and acquire good mechanical resistance in a few hours. On the other hand, mining in Peru is one of the most important industries due to its contribution to the economic development of the country. However, mining is also one of the industries with the greatest negative impact on the environment, mainly due to the enormous amount of inorganic waste that it generates and which is currently accumulated without any prospect of recycling or reuse. Therefore, this research was conducted to elaborate concretes from mining tailings and to evaluate their mechanical behavior in creep (between 500 and $600{ }^{\circ} \mathrm{C}$ ). The results obtained allow us to propose the use of mining tailings for the elaboration of geopolymeric thermal barriers that work in conditions of intermediate temperatures, up to $600{ }^{\circ} \mathrm{C}$.
\end{abstract}

Keywords: Construction, creep, geopolymer concrete, mining tailings.

\section{Introduction}

Geopolymer is a class of synthetic and inorganic materials obtained at room temperature by a chemical process which involves the solubilization of amorphous phases of aluminosilicates present in industrial solid waste, calcined clays, natural minerals, among others, by the action of an agent of alkaline activation [1,2]. Geopolymers have been attracting the attention of the scientific community in recent years, due to the variety of applications in which they can be used, this derived from their excellent fire resistance, low density, low cost, easy manufacturing, excellent chemical stability. I thermal and eco-friendly synthesis [3,4].

In recent years, geopolymers have being investigated as alternative materials to Portland cement $[5,6]$ and in various applications in the construction industry. Several works have reported that geopolymeric concretes have the capacity to develop up to $70 \%$ of maximum compressive strength within the first 4 hours of curing [7], compared to Portland cement concretes that require up to 28 days to achieve their maximum mechanical resistance. On the other hand, geopolymeric concrete shows very little shrinkage due to drying, it was found that after one year it presents between 5 to 7 times less shrinkage than Portland cement concrete [8,9]. The negative influence of sulfates on Portland cement concrete has been reported, which drastically reduces its mechanical resistance, which is explained by the reaction of sulfates with the calcium present in Portland cement and which leads to the formation of phases of greater volume (gypsum and ettringite), which in turn generate cracks within the material [10], on the other hand, geopolymeric concrete does not present this type of problem because its properties depend on other types of reactions (in the absence of calcium) [11.12].

Geopolymeric concretes exhibit good mechanical response to high temperatures compared to their Portland cement concrete counterparts; in this regard, Kong et al. [12] studied the mechanical response of geopolymeric and Portland cement pastes after being subjected to high temperatures, finding that while at $800{ }^{\circ} \mathrm{C}$ the geopolymeric paste improves its 
resistance to compression, the Portland cement paste, at $400{ }^{\circ} \mathrm{C}$, lost all its residual resistance, this loss of resistance of the Portland cement paste was attributed to the decomposition of $\mathrm{Ca}(\mathrm{OH})_{2}$ at approximately $400{ }^{\circ} \mathrm{C}$.

Among the most important components of conventional concrete the presence of Portland cement stands out, basically a mixture of gypsum and Clinker, the latter is obtained by calcining limestone and clay at temperatures between 1350 and $1450{ }^{\circ} \mathrm{C}$. Obtaining the Clinker is accompanied by large $\mathrm{CO}_{2}$ emissions. In this regard, it has been determined that a cement furnace produces approximately 0.8 tons of $\mathrm{CO}_{2}$ for every ton of Portland cement [13]. On the other hand, the accumulation of large amounts of mining tailings, as a consequence of mining in Peru constitutes one of the main environmental problems in our region. Currently, there is not an adequate mining waste management system, therefore, it is important to propose new alternatives for the use of this waste [14-16]. In this sense, this work is very important for the environmental care of Peru.

\section{Materials and methods}

\subsection{Raw material and matrix of mixtures}

Geopolymeric concretes (GCs) were manufactured by geopolymerizing mining tailings dust (MT) and an alkaline solution of 9 molar $\mathrm{Na}(\mathrm{OH})$, with the addition of a controlled amount of fine sand (FS). The experimental Simplex Lattice design was used to determine the matrix of GC mixtures. This design allows defining volumetric concentrations in a mixture. To convert the volumetric concentrations into mass concentrations, the real density of the precursor materials was determined. The real density was determined using a glass pycnometer and distilled water. In addition, equation 1 was used.

$$
\begin{aligned}
& \text { Density }=\frac{\left(m_{B}-m_{A}\right)}{\left(m_{B}-m_{A}\right)+\left(m_{C}-m_{D}\right)} \times \rho_{\text {water }} \\
& \rho_{\text {water }}=\text { water temperature use }
\end{aligned}
$$

where:

$\mathrm{m}_{\mathrm{A}}=$ measurement of the mass of the clean, dry and empty pycnometer and the stopper.

$\mathrm{m}_{\mathrm{B}}=$ measurement of the mass of the dry pycnometer, the test sample and the stopper.

$\mathrm{m}_{\mathrm{C}}=$ measurement of the mass of the pycnometer filled with distilled water until it is level and the stopper.

$m_{D}=$ measurement of the mass of the pycnometer, test sample, the stopper and distilled water until it is level. In this last measure, it must be ensured that there are no air bubbles and in all measures ensure that the external surface of the pycnometer is completely dry and clean.

The values found for the real average density of MT and FS were 2.83 and $3.07 \mathrm{~g} / \mathrm{cm}^{3}$, respectively, and were used to determine the most important substances of the raw materials shown in Table 1.

Table 1: Composition of the materials prepared in this research.

\begin{tabular}{l|c|c|c|c|c|c}
\hline \multirow{2}{*}{\multicolumn{1}{c|}{ sample }} & \multicolumn{2}{|c|}{ volume (\%) } & \multicolumn{2}{c|}{ weight (\%) } & \multicolumn{2}{c}{ weight (g.) } \\
\cline { 2 - 7 } & MT & FS & MT & FS & MT & FS \\
\hline GC-MT25 & 25.0 & 75.0 & 23.5 & 76.5 & 4.7 & 15.3 \\
GC-MT37.5 & 37.5 & 62.5 & 35.7 & 64.3 & 7.1 & 12.9 \\
GC-MT50 & 50.0 & 50.0 & 48.0 & 52.0 & 9.6 & 10.4 \\
GC-MT62.5 & 62.5 & 37.5 & 60.6 & 39.4 & 12.1 & 7.9 \\
GC-MT75 & 75.0 & 25.0 & 73.5 & 26.5 & 14.7 & 5.3 \\
\hline
\end{tabular}

\subsection{Elaboration of geopolymeric concrete}

The MT used in this research was provided by CEPROMET SAC (Peruvian company dedicated to the transformation of gold minerals) and the FS was acquired from a local hardware store. MT and FS were ground separately and then sieved through ASTM No. 140 mesh. The elaboration of GC samples began by measuring adequate amounts of MT and FS (based on $20 \mathrm{~g}$ and according to Table 1). For each type of GC samples, MT and FS were dry mixed for 5 minutes and then $5 \mathrm{ml}$ of 9 molar $\mathrm{Na}(\mathrm{OH})$ solution was added, mixing was continued for an 
additional 5 minutes until obtaining a workable and homogeneous paste. The geopolymeric pastes were pressed at $20 \mathrm{MPa}$ and for 5 minutes in a $20 \mathrm{~mm}$ diameter cylindrical steel mold. After the demolding process, the samples were placed in hermetic bags at room temperature for 24 hours and then they were oven dried at $80{ }^{\circ} \mathrm{C}$ for another 24 hours.

\subsection{Physical, morphological and mechanical characterization of geopolymeric concrete}

The physical characterization of the GCs consisted of determining their geometric density from the measurement of the dimensions and masses of three samples. Morphological characterization was performed on polished GC surfaces, for which the metallographic preparation of the surfaces began, which consisted of two stages: (i) roughing with SiC abrasive paper (\# 600, \# 800 and \# 1200) and (ii) mechanical polishing with cloths, polishing slurry and 6, 3 and 1 micron particle

size diamond paste. The surfaces, after polishing, were cleaned with distilled water and dried in the sun. Finally, the polished and dry surfaces were observed in a light microscope in reflection mode.

The mechanical characterization carried out in this research consisted of creep tests at constant load and temperatures between 500 and $600{ }^{\circ} \mathrm{C}$. All tests were performed after 28 days of curing of the GCs. In general, creep tests allow evaluating the deformation rate of materials when subjected to constant stress and temperature conditions. By subjecting a material to constant stress, microscopic mechanisms are activated, allowing it to accommodate external stress through its stationary deformation (creep). The creep of materials at room temperature is too slow and it takes several years to study it adequately, however, there are modern creep equipment that allows the material deformation process to be accelerated, including temperature as an independent variable. All creep tests were performed on 5x5x10 mm parallelepiped samples.

In order to evaluate the microscopic mechanisms of stationary deformation in the GC samples, it was necessary to define stress and temperature ranges in which these mechanisms become important. In this research, prior to creep studies, the maximum resistance to uniaxial compression of GC samples as a function of temperature was studied. In these first tests the GCs were subjected to forced deformation at a constant compression rate of $0.05 \mathrm{~mm} / \mathrm{min}$ and temperatures of 500 and $600{ }^{\circ} \mathrm{C}$ until the material fractured. With the results obtained at constant compression rate, it was possible to determine the stress and temperature ranges for the creep tests.

\section{Results and discussions}

\subsection{Physical and morphological characterization}

Regarding the physical characterization of the GC samples, it was not possible to identify a correlation between the initial volumetric composition (Table 1) and the average geometric density. In general, all the GCs studied in this research presented geometric densities of around $1.90 \mathrm{~g} / \mathrm{cm}^{3}$.

The morphology of the GCs studied consisted of two well-differentiated phases: (i) a continuous phase in dark contrast corresponding to the geopolymer (MT) and (ii) scattered particles in light contrast which are located within the continuous phase and correspond to the FS. The continuous dark geopolymer phase is made up of fairly small particles compared to the size of the FS particles. It should be noted that a direct correlation has been observed between the presence of light contrast dispersed particles and the initial volumetric percentage of FS, that is, as the volumetric fraction of FS increases from 25\% (CG-MT75) to 75\% (CG-MT25) also increases the presence of scattered particles of clear contrast in the micrographs obtained by light microscopy (Figure 1). 

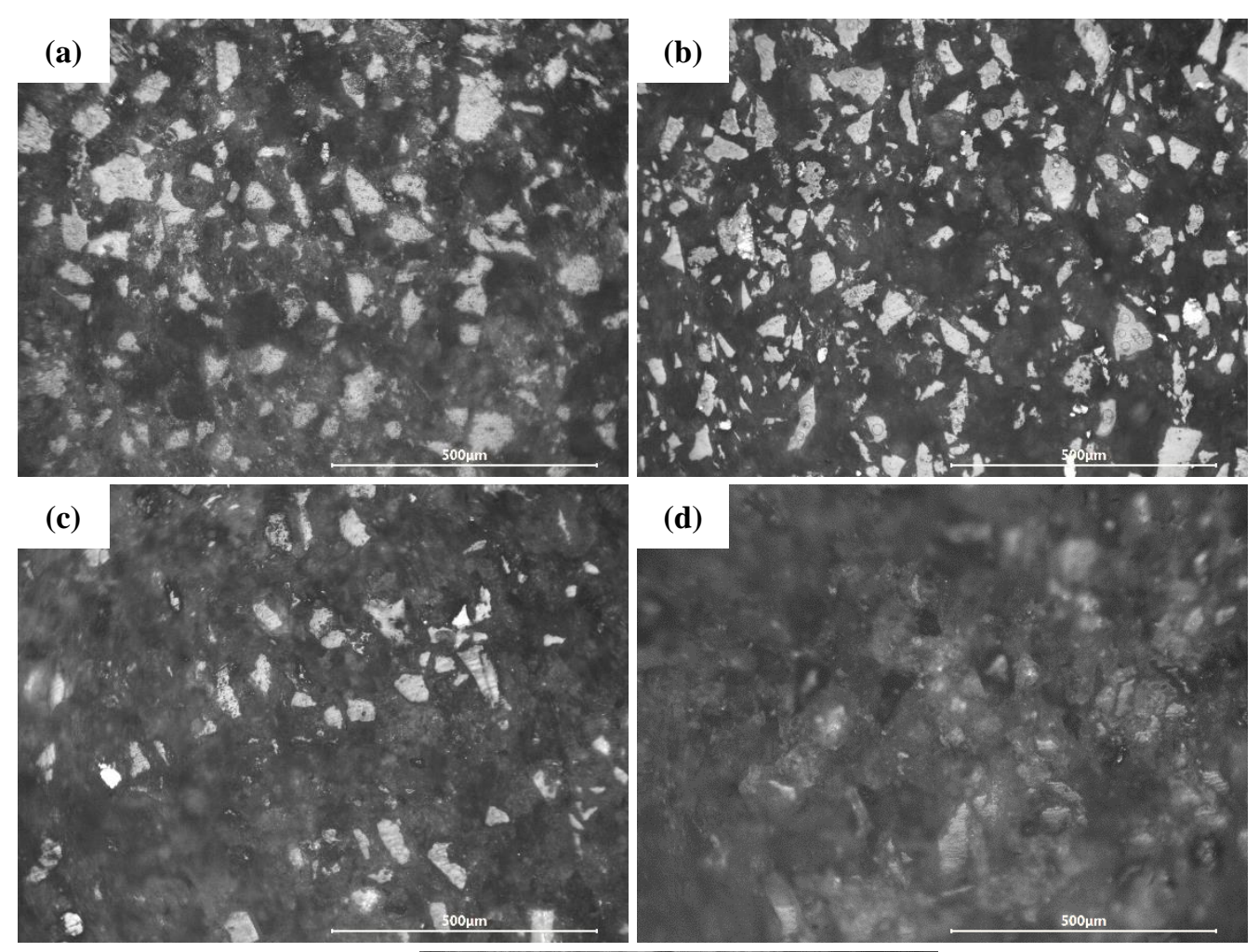

(e)

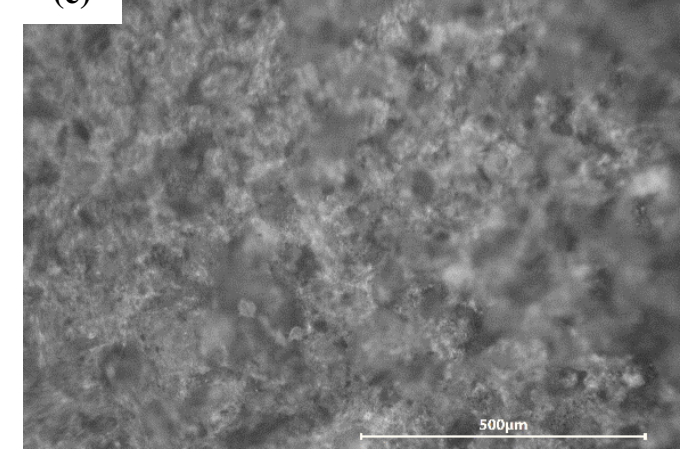

Fig. 1: Micrographs by optical microscopy of five types of GCs. (a) GC-MT25, (b) GC-MT37.5, (c) GC-MT50, (d) GC-MT62.5, and (e) GC-MT75.

\subsection{Geopolymer concrete creep}

As mentioned in section 2.3, uniaxial compression tests at constant compression rate and at temperatures between 500 and $600{ }^{\circ} \mathrm{C}$ were carried out before the creep tests. Figure 2 reports the results for all the GCs studied. A totally fragile mechanical behavior has been found when the GCs were tested at $500{ }^{\circ} \mathrm{C}$ (figure 2 (a)) and completely ductile when they were tested at $600{ }^{\circ} \mathrm{C}$ (figure $2(\mathrm{~b})$ ), this result suggested a transition stage in the mechanisms microscopic against external stress by increasing the test temperature from 500 to $600{ }^{\circ} \mathrm{C}$. Based on these results, it was decided to delimit the parameters for creep tests to the temperature range between 500 and $600{ }^{\circ} \mathrm{C}$, and it was also determined that the range of stresses optimum for all creep tests is between 20 and $40 \mathrm{MPa}$ Finally, Table 2 summarizes the parameters used in the creep tests carried out in this research. 

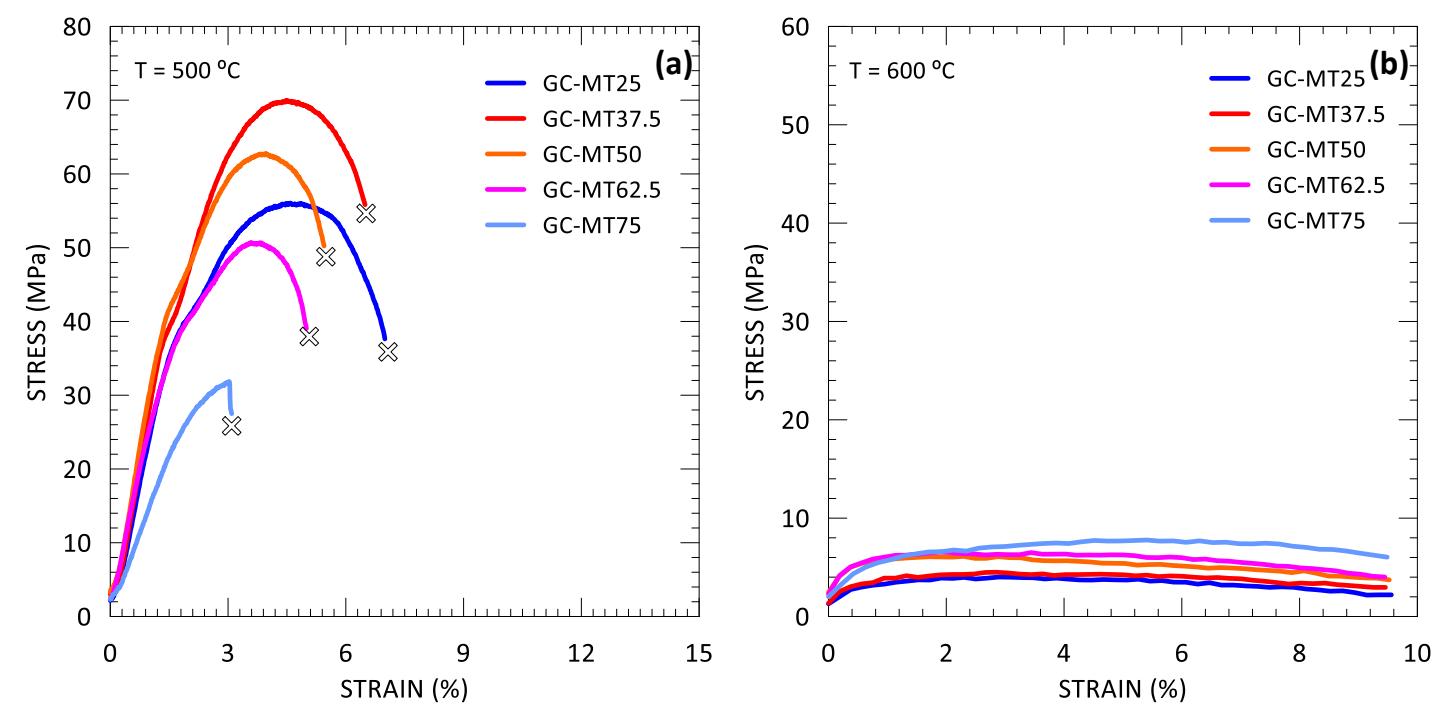

Fig. 2: Stress vs. strain curves of GCs tested at (a) 500 and (b) $600{ }^{\circ} \mathrm{C}$.

Table 2: Experimental conditions for GCs creep tests.

\begin{tabular}{|c|c|c|}
\hline Type of test & Temperature $\left({ }^{\circ} \mathrm{C}\right)$ & Stress (MPa) \\
\hline type I & 525 & 40 \\
\hline type II & 575 & 20 \\
\hline
\end{tabular}

The development of the type I creep tests had the following stages (i) controlled heating of the sample to $525^{\circ} \mathrm{C}$ at a constant rate of $10^{\circ} \mathrm{C} / \mathrm{min}$., (ii) isotherm at $525^{\circ} \mathrm{C}$ for 1 hour until thermal equilibrium, (iii) compression of the sample up to $40 \mathrm{MPa}$ and at a temperature of $525^{\circ} \mathrm{C}$ and (iv) steady flow at constant temperature and stress.

Figure 3 shows strain vs. time curves and show the different mechanical responses in creep of the GCs to a constant external stress, it is clearly observed that the increase of the geopolymer phase (MT activated with a solution of $\mathrm{Na}(\mathrm{OH})$ ) in the GCs, leads to a greater strain in a shorter period of time.

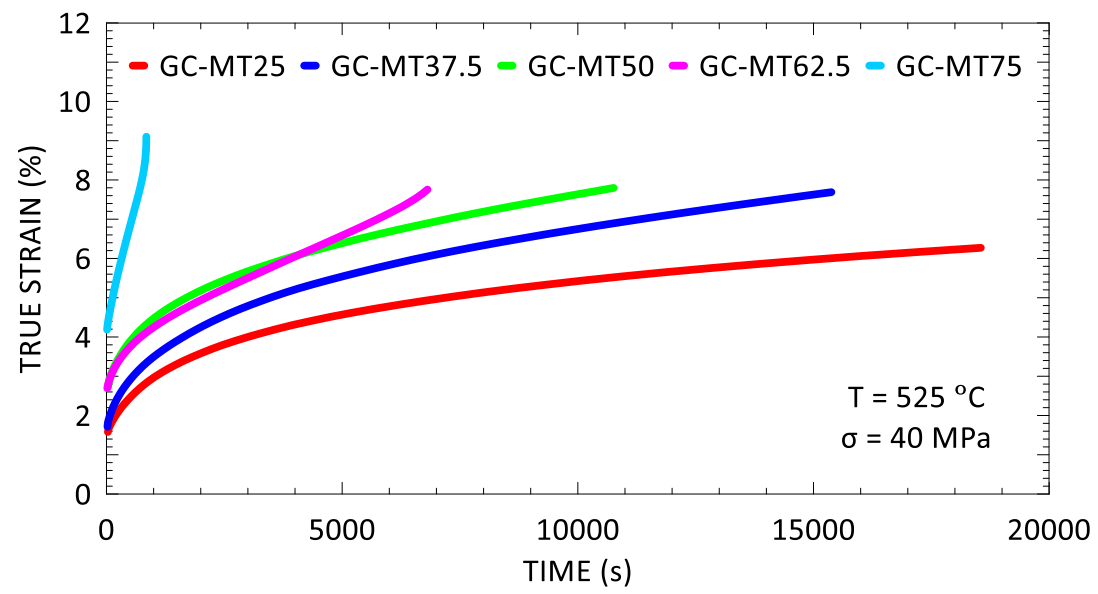

Figure 3: true strain vs. time curves for GC samples tested in creep at $525^{\circ} \mathrm{C}$ and $40 \mathrm{MPa}$.

On the other hand, figure 4 presents strain rate vs. strain or simply creep curves for the five types of GCs studied. 


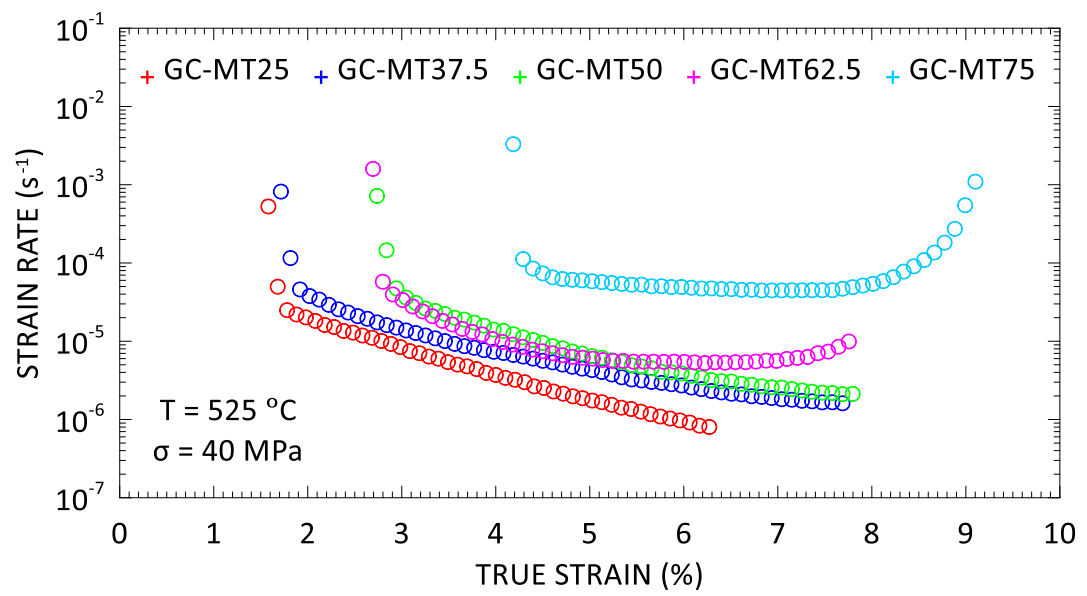

Figure 4: Strain rate vs. true strain curves for GCs samples tested in creep at $525^{\circ} \mathrm{C}$ and $40 \mathrm{MPa}$.

In all creep tests, three deformation states can be identified: (i) the first is called primary or transient creep and is characterized by a rapid decrease in the strain rate after the initial application of the load, (ii) the second is called secondary or stationary creep and is the one described by the general equation of the steady state of plastic deformation (equation 2):

$$
\dot{\varepsilon}=A \sigma^{\mathrm{n}} \mathrm{d}^{-\mathrm{p}} \exp \left(-\frac{\mathrm{Q}}{\mathrm{RT}}\right)
$$

Where $\mathrm{A}$ is a constant, $\mathrm{R}$ the universal gas constant and the parameters $\mathrm{n}, \mathrm{p}$ and $\mathrm{Q}$ are the stress exponent, the grain size exponent and the activation energy, respectively. Actually, the stationary strain rate is independent of time in constant tension tests, but not in constant load experiments (such as those carried out in this research) since the section of the sample increases with time. Therefore, in a representation Ln $\dot{\varepsilon}-\varepsilon$ (strain rate vs. strain) of an ideal creep test, the stationary deformation rate decreases linearly with deformation, with a slope equal to the opposite of the stress exponent $\mathrm{n}$ and (iii) the third stage of the creep process corresponds to a rapid increase in the strain rate as a consequence of nucleation and coalescence of cavities that, eventually, ends with the breakage of the material; This regime is called tertiary or type III creep.

In our research, the creep studies carried out at $525^{\circ} \mathrm{C}$ and $40 \mathrm{MPa}$ on the GCs shown in Figure 4 have allowed to obtain values of the stress exponent $\mathrm{n}$ of $0.8,0.7,0.6,0.5,0.3$ and 0.2 for the GCs with volumetric percentages of MT of $25,37.5,50,62.5$ and 75 , respectively. These values of $n$ suggest that the main strain mechanism in this type of materials is diffusion at grain boundaries.

Type II creep tests had the following stages (i) controlled heating of the sample to $575{ }^{\circ} \mathrm{C}$ at a constant rate of 10 ${ }^{\circ} \mathrm{C} / \mathrm{min}$., (ii) isotherm at $575^{\circ} \mathrm{C}$ for 1 hour until thermal equilibrium, (iii) compression of the sample up to $20 \mathrm{MPa}$ and at a temperature of $575^{\circ} \mathrm{C}$ and (iv) steady flow at constant temperature and stress.

The strain vs. time curves shown in figure 5 does not show a direct relationship between the percentage of geopolymeric phase and the strain rate of GCs, although as seen in figure 5, the GC with 75 vol.\% MT (GC-MT75) is deformed and fails prematurely compared to others with lower geopolymer phase concentrations. Figure 6 shows creep curves at $575{ }^{\circ} \mathrm{C}$ and $20 \mathrm{MPa}$ for all the GCs tested, it can be noticed that in no case was it possible to enter a steady state of plastic deformation, going directly from the state of initial transient creep to that of tertiary creep or of material rupture, therefore, it was not possible to determine the exponents of tension $\mathrm{n}$ from these creep curves. 


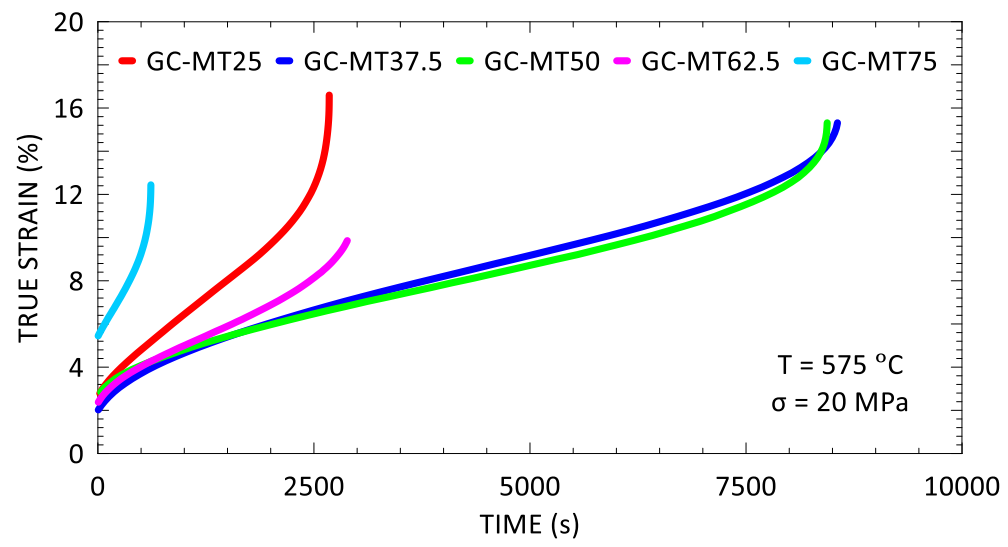

Fig. 5: True strain vs. time curves for GCs samples tested in creep at $575^{\circ} \mathrm{C}$ and $20 \mathrm{MPa}$.

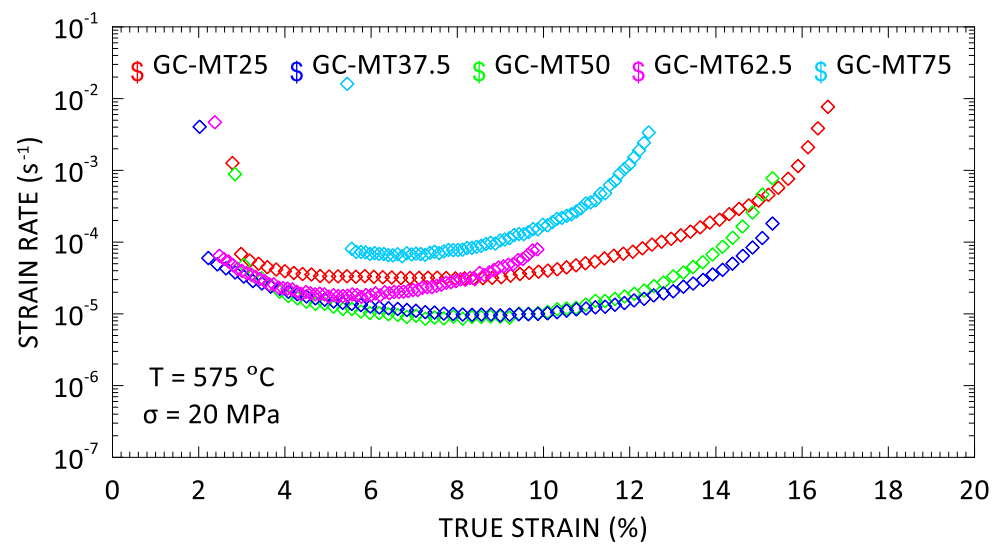

Fig. 6: Strain rate vs. true strain curves for GCs samples tested in creep at $575^{\circ} \mathrm{C}$ and $20 \mathrm{MPa}$.

\section{Conclusions}

Geopolymeric concretes have been successfully elaborated from the geopolymerization of mining tailings powders with a 9 molar solution of sodium hydroxide as a hardening agent and without the addition of Portland cement.

It was not possible to find a correlation between the geometric density of the studied geopolymeric concretes and the volumetric fractions of the precursor components. In general, the average density of all the studied geopolymeric concretes was $1.9 \mathrm{~g} / \mathrm{cm}^{3}$.

The morphology found in the geopolymeric concretes consisted of two well differentiated phases, one of dark contrast and continuous geopolymer and the other of individual and dispersed light contrast particles located within the continuous geopolymer phase. The geopolymer phase is formed from very small mining tailings particles, in addition there is a direct correlation between the presence of clear contrast particles and the initial volume fraction of fine sand in the manufactured geopolymeric concrete, therefore, the individual particles correspond to added fine sand.

A totally fragile mechanical response was identified when the geopolymeric concretes were tested at $500{ }^{\circ} \mathrm{C}$ and completely ductile when they were tested at $600{ }^{\circ} \mathrm{C}$, this result suggests an evolution in the microscopic mechanisms of deformation against external stress when increasing the test temperature from 500 to $600{ }^{\circ} \mathrm{C}$.

The creep studies carried out at $525^{\circ} \mathrm{C}$ and $40 \mathrm{MPa}$ allowed obtaining values of the stress exponent $\mathrm{n}$ of $0.8,0.7,0.6$, 0.5, 0.3 and 0.2 for geopolymeric concretes with volumetric percentages of mining tailings of 25, 37.5, 50, 62.5 and 75, respectively. These values of $\mathrm{n}$ suggest that the main deformation mechanism in this type of materials is diffusion at grain boundaries.

In the creep studies carried out at $575^{\circ} \mathrm{C}$ and $20 \mathrm{MPa}$ for all the geopolymeric concretes studied, it was not possible to enter a stationary state of plastic deformation, going directly from the state of initial transient creep to that of tertiary creep. Therefore, under these creep test conditions it has not been possible to determine values for the stress exponents $n$. 


\section{Acknowledgements}

This work was founded by CONCYTEC - FONDECYT within the framework of call E041-01 with contract $\mathrm{N}^{\circ}$ 36-2018-FONDECYT-BM-IADT-AV and was executed in the laboratories of the Universidad Católica San Pablo.

\section{References}

[1] J. Davidovits, M. Davidovics, "Geopolymer: ultra-high temperature tooling material for the manufacture of advanced composites", Sampe 36 (2) (1991), pp. 1939-1949.

[2] Hamdy K. Shehab, Ahmed S. Eisa, Ahmed M. Wahba, "Mechanical properties of fly ash based geopolymer concrete with full and partial cement replacement", Construction and Building Materials, vol. 126, 2016, pp. 560-565.

[3] Bo Wei, Yimin Zhang, Shenxu Bao, "Preparation of geopolymers from vanadium tailings by mechanical activation", Construction and Building Materials, vol. 145, 2017, pp. 236-242.

[4] Jingkun Yuan, Peigang He, Peifeng Zhang, Dechang Jia, Delong Cai, Zhihua Yang, Xiaoming Duan, Shengjin Wang, Yu Zhou, "Novel geopolymer based composites reinforced with stainless steel mesh and chromium powder", Construction and Building Materials, vol. 150, 30 September 2017, pp. 89-94.

[5] Bo Wei, Yimin Zhang, Shenxu Bao, "Preparation of geopolymers from vanadium tailings by mechanical activation" Construction and Building Materials, vol. 145, 2017, pp. 236-242.

[6] F.N. Okoye, "Geopolymer binder: A veritable alternative to Portland cement", Materials Today: Proceedings, vol. 4, Issue 4, Part E, 2017, pp. 5599-5604.

[7] Davidovits J., "Properties of Geopolymer Cements", First International Conference on Alkaline Cements and Concretes, 1994, pp.131-149.

[8] Wallah SE, "Drying Shrinkage of Heated-Cured Fly Ash-Based Geopolymer Concrete", Modern Applied Science 2009;3(12), pp. 14-21.

[9] Ferraris CF, Clifton JR, Stutzman PE, Garboczi EJ, "Mechanisms of degradation of Portland cement-based systems by sulfate attack", Mechanisms of Chemical Degradation of Cement-Based systems 1997; pp. 185-192.

[10] T. Bakharev, "Durability of geopolymer materials in sodium and magnesium sulfate solutions", Cement and Concrete Research, vol. 35, Issue 6, 2005, pp. 1233-1246.

[11] Wallah SE and Rangan BV, "Low-calcium fly ash-based geopolymer concrete long-term properties", Research Report GC2, Faculty of Engineering, Curtin University of Technology, 2006.

[12] Kong DLY and Sanjayan JG., "Effect of elevated temperature son geopolymer paste, mortar and concrete", Cement and Concrete Research 2010;40(2), pp. 334-339.

[13] Jeff Borger, Ramon L. Carrasquillo, David W. Fowler., "Use of recycled wash water and returned plastic concrete in the production of fresh concrete", Advanced Cement Based Materials, vol. 1, Issue 6, 1994, pp. 267-274.

[14] Mónica Moreno-Brush, Johan Rydberg, Nadia Gamboa, Ilse Storch, Harald Biester, "Is mercury from small-scale gold mining prevalent in the southeastern Peruvian Amazon?, Environmental Pollution, vol. 218, 2016, pp. 150-159.

[15] Joni Safaat Adiansyah, Michele Rosano, Sue Vink, Greg Keir, Jason R. Stokes, "Synergising water and energy requirements to improve sustainability performance in mine tailings management", Journal of Cleaner Production, vol. 133, 2016, pp. 5-17.

[16] Joni Safaat Adiansyah, Michele Rosano, Sue Vink, Greg Keir, "A framework for a sustainable approach to mine tailings management: disposal strategies", Journal of Cleaner Production, vol. 108, Part A, 2015, pp. 1050-1062. 